\title{
Meiofauna metabarcoding in Lima estuary (Portugal) suggests high taxon replacement within a background of network stability
}

\author{
Maria Fais a,b,c,*, Bruno Bellisario $^{\mathrm{a}, \mathrm{b}, \mathrm{d}, *}$, Sofia Duarte ${ }^{\mathrm{a}, \mathrm{b}}$, Pedro Emanuel Vieira ${ }^{\mathrm{a}, \mathrm{b}}$, \\ Ronaldo Sousa ${ }^{\mathrm{a}, \mathrm{b}}$, Carlos Canchaya ${ }^{\mathrm{c}}$, Filipe Oliveira Costa ${ }^{\mathrm{a}, \mathrm{b}, *}$ \\ ${ }^{a}$ Centre of Molecular and Environmental Biology (CBMA), University of Minho, Portugal \\ ${ }^{\mathrm{b}}$ Institute of Science and Innovation for Bio-Sustainability (IB-S), University of Minho, Portugal \\ ${ }^{\mathrm{c}}$ Department of Biochemistry, Genetics and Immunology, University of Vigo, Spain \\ ${ }^{\mathrm{d}}$ Department of Ecological and Biological Sciences (DEB), University of Viterbo, Italy
}

\section{A R T I C L E I N F O}

\section{Article history:}

Received 10 March 2020

Received in revised form 25 May 2020

Accepted 15 June 2020

Available online 20 June 2020

\section{Keywords:}

Estuarine ecosystems

Meiofauna

Spatial and temporal variation

eDNA metabarcoding

Network analysis

\begin{abstract}
A B S T R A C T
Meiofauna organisms play an important role in ecological and sedimentary processes in estuarine ecosystems. Recently, the application of environmental DNA (eDNA) for investigating meiofauna in different environments, improved the accessibility to its diversity and composition in a scale, frequency and depth previously unattainable. Nevertheless, little attention has been given to the description of baseline patterns of coupled spatial and temporal dynamics of meiobenthic communities. In an earlier study conducted in Lima estuary (NW Portugal), using eDNA metabarcoding of sediment samples, high levels of meiofauna Operational Taxonomic Units (OTUs) turnover were recorded, between sampling points only a few metres apart, and among sampling stations along the estuary. In order to verify the consistency of these patterns, in the current study we re-assessed Lima estuary's meiofauna communities approximately 1 year after, applying the same methodological approach (targeting segments of the COI and 18S rRNA genes), and expanding HTS-data analyses through the use of association networks. A high degree of spatial turnover was found both within and between sampling stations and this was consistent for both markers and years. As a consequence, most of the betadiversity was accounted by OTU replacement with only a minor contribution from OTU richness. Despite the high levels of OTU replacement, relatively stable network properties were found in meiofaunal communities, irrespective of the sampled year. Network properties appear to shift sharply from the downstream/high salinity area of the estuary to the mesohaline medium-upstream areas, suggesting high resilience and redundancy of meiofaunal communities along the estuarine gradient. The recognition of meiofauna's networks features may improve the understanding of the ecology and dynamics of these communities that apparently hold large portions of variable elements, thereby making difficult their analyses solely based on the OTU/species composition.
\end{abstract}

(c) 2020 Elsevier B.V. All rights reserved.

\section{Introduction}

Among the components of the benthic domain, meiofauna plays an important role in ecological, trophic and sedimentary processes (Schratzberger and Ingels, 2018). Meiobenthos comprises both small typical marine metazoans and large protists, and juvenile stages or encystments of macrobenthic organisms, characterized by morphological and functional adaptation to the interstitial life (Giere, 2009). Earlier ecological studies have shown the importance of meiofauna in terms of biomass contribution in the food chain and bioturbation (Gerlach, 1971; Schratzberger

\footnotetext{
* Corresponding authors at: Centre of Molecular and Environmental Biology (CBMA), University of Minho, Portugal.

E-mail addresses: maria.fais@bio.uminho.pt (M. Fais), bruno.bellisario@gmail.com (B. Bellisario), fcosta@bio.uminho.pt (F.O. Costa).
}

and Ingels, 2018), as biological resource (Coull, 1999; Heip et al., 1985 ) and bioindicator of anthropogenic disturbances on marine and coastal ecosystems (Danovaro et al., 2004). Despite their limited reproductive output and dispersion, many meiofauna taxa have cosmopolitan distributions and rapid generational turnover (Fenchel and Finlay, 2004; Giere, 2009). Environmental features and biological interactions play an important role in the spatial and temporal distribution of meiofaunal communities at local scale, especially in naturally and anthropogenically-stressed environments, such as estuaries. A combination of factors, such as salinity and precipitation, tidal exposure, food availability and content in organic matter, oxygen, nutrients, and trophic interactions (predation, parasitism, competition) determine the spatial distribution and seasonal turnover of meiofaunal communities (Giere, 2009 and references therein). 
Despite its potential and relevance for assessing ecological quality status in coastal ecosystems, meiofauna has not been included in most of the established broad-scale national or supranational environmental monitoring frameworks (Moreno et al., 2011; Pusceddu et al., 2007; Schratzberger, 2012; Ürkmez et al., 2015). The limited accessibility and taxonomic knowledge of the meiofauna has been hampering a comprehensive understanding of the spatial and temporal dynamics of the whole benthic domain and, consequently, the protection of the full sweep of diversity in that important component of coastal ecosystems (Gibson et al., 2015). Morphology-based approaches have been insufficient to gain an in-depth knowledge on patterns of variability at the local and global scale of these taxonomically-challenging meiofaunal communities (Leasi et al., 2018; Zeppilli et al., 2015; Zeppilli and Leduc, 2018). In recent years, the development and application of DNA-based methods for biological identifications, such as DNA metabarcoding, has made possible the simultaneous identification of multiple organisms from bulk samples (Hajibabaei et al., 2012), from community DNA (Andújar et al., 2018), or indirectly from environmental DNA (Taberlet et al., 2018). Notably, the application of DNA metabarcoding for investigating meiofauna from different environments improved the accessibility to its diversity and composition in a scale, frequency and depth previously unattainable (Haenel et al., 2017; Lallias et al., 2015; Leasi et al., 2018; Nascimento et al., 2018). Nevertheless, little attention has been given so far to the description of baseline patterns of coupled spatial and temporal dynamics of meiobenthic communities (Guardiola et al., 2016).

Although species richness can be considered a key element in applied and conservation ecology, the total number of species per se may show high temporal and spatial variability, strongly influencing their spatial arrangement of species and the pattern of coexistence between co-occurring species; this situation may be especially true in estuaries (Sousa et al., 2008; Costa-Dias et al., 2010; Ilarri et al., 2014). Change in species across space can be determined by different mechanisms related to what extent species replacement, nestedness and richness concur in determining the observed patterns of beta-diversity (Legendre, 2014). For instance, environmental filtering, competition and historical events can lead to a high replacement (i.e., turnover) of species, while niche availability might influence species richness in space. Therefore, partitioning beta-diversity into different components may allow for a more comprehensive understanding of the mechanisms driving diversity patterns and species co-existence.

A promising avenue to better understand and disentangle the role of different mechanisms on the coexistence of species is the possibility to reconstruct association networks from cooccurrence data, assuming that dissimilarities caused by species turnover should influence the overall dissimilarity in co-occurrences between networks (Poisot et al., 2012). Although co-occurrence networks cannot reveal real biotic interactions, they may be particularly valuable in identifying community assembly processes (Freilich et al., 2018; Sander et al., 2017), or the effects of natural and anthropogenic disturbance on community structure (Tulloch et al., 2018).

In an earlier metabarcoding study on meiofaunal communities in Lima estuary (NW Portugal; Fais et al., 2020), we recorded unexpectedly high levels of Operational Taxonomic Units (OTUs) replacement between sampling points only a few metres apart (4-5 $\mathrm{m}$ ), and among sampling stations along the estuarine gradient. In order to verify the consistency of these patterns, we reassessed Lima estuary's meiofaunal communities circa one year after (June 2017-June 2018), applying the same methodological approach targeting two molecular markers (selected segments of
COI and 18S rRNA genes), and surveying exactly the same sampling stations. Here, we used beta-diversity partitioning and network analysis to gain insight into the inner structural properties of meiofaunal communities. Results showed an apparent stability of association network features despite the high spatial and temporal replacement of OTUs. Overall, the combined use of metabarcoding data and network analysis may constitute a particularly fit and productive supplement for meiofauna's metabarcodingbased monitoring, considering the typically high-rank taxonomic assignments, due to low reference library completion (McGee et al., 2019; Weigand et al., 2019) and the uncertainty about specimen abundance inferences (Bik et al., 2012; Elbrecht and Leese, 2015).

\section{Material and methods}

\subsection{Study area and environmental characterization}

Sampling campaigns took place in the Lima estuary (NW Portugal; Figure S1), an estuarine system characterized by comparatively moderate anthropogenic disturbance (Sousa et al., 2006, 2007; Costa-Dias et al., 2010). Salinity in the Lima estuary usually varies according to tides action and river flows, which depends on the spatial and temporal distribution of rainfalls (Vieira and Pinho, 2010). For the purpose of this study, sampling of intertidal sediments was carried out during low tide conditions, in the same month (June) in 2017 and 2018, in four stations of Lima

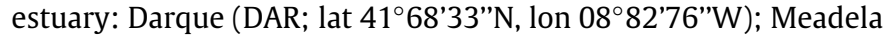
(MEA; lat 4169'51"N, lon 0881'12”W); Santa Marta de Portuzelo (POR; lat $41^{\circ} 69^{\prime} 78^{\prime \prime} \mathrm{N}$, lon $08^{\circ} 77^{\prime} 18^{\prime} \mathrm{W}$ ) and Serreleis (SER; lat $41^{\circ} 77^{\prime} 18^{\prime} \mathrm{N}$, lon $08^{\circ} 74^{\prime} 93^{\prime \prime} \mathrm{W}$ ).

A nonparametric two-way ANOVA based on aligned rank transformation (ART; Wobbrock et al., 2011) was used to test for the effect of fixed factors (years, sampling stations and their interaction) on environmental parameters (salinity, grain's size and total organic matter). For each effect, ART computes a separated aligned response variable by transforming it into a ranking and applies a separate ANOVA to check for the significance of the corresponding effect. Differently from other nonparametric alternatives that allow for a comparison only among main effects (e.g., Kruskal-Wallis and Friedman tests), ART can be used to examine interaction effects by correcting for increasing Type I errors (false positive; Wobbrock et al., 2011).

\subsection{Sample collection and DNA extraction}

Three replicates, containing the first $5 \mathrm{~cm}( \pm 0.5 \mathrm{~cm})$ of intertidal sediments, were sampled from each station directly into $50 \mathrm{~mL}$ sterile Falcon ${ }^{\circledR}$ tubes $(3 \mathrm{~cm} \varnothing)$, about $5 \mathrm{~m}$ apart from each other (12 samples/year). Additional sediment samples were collected to assess the total organic matter (TOM) and granulometry (Supplementary Material, Table S1), as described in Fais et al. (2020). Salinity was measured in surface water of the lower tidal zone at each sampling station using a Multiparameter Sea Gauge YSI EXO 2. DNA was extracted directly from $10.0 \mathrm{~g}$ of sediment, using the QIAGEN ${ }^{\circledR}$ PowerMax Soil DNA Isolation kit (cat\#12988-10), following the manufacturer's instructions except for the usage of a multi-tube vortex during the lysis step, and setting up of the posterior centrifugation to $5 \mathrm{~min}$. Negative extraction controls were performed during this step, by using exactly the same procedure, but without sediment, for checking for contamination of the solutions of the DNA extraction kits and labware materials used. These negative controls were further used during PCR reactions. 


\subsection{Molecular and bioinformatic procedures}

The primer pairs miCOIintF/LoboR1 (Leray et al., 2013; Lobo et al., 2013) and TAReuk454FWD1/TAReukREV3 (Lejzerowicz et al., 2015; Stoeck et al., 2010) were used to amplify an internal region of 313 bp of the mitochondrial cytochrome c oxidase I (COI) and the V4 hypervariable region of the 18S rRNA gene $(\sim 400$ bp), respectively (Supplementary Material, Table S2). Negative controls were tested during the first and the second amplification reactions, which followed the conditions described in Table S3 (Supplementary Material). First, PCR products were purified and normalized in a SequelPrep 96-well plate kit (ThermoFisher Scientific, Waltham, USA), before being pooled and paired-end sequenced in the Illumina MiSeq ${ }^{\circledR}$ platform, according to manufacturer's instructions (Illumina, 2013). Amplicon libraries were obtained for a total of 48 samples (3 sampling units per station and per marker locus). The 313 bp (COI) and $\sim 400$ bp (V4) amplified fragments were purified and quantified through the AMPure XP beads (Agencourt, Beckman Coulter, USA) and PicoGreen dsDNA quantitation kit (Invitrogen, Life Technologies, Carlsbad, California, USA), respectively. Sequencing adapters and low-quality reads ( $\leq 150$ bp and $\leq \mathrm{Q} 25$ in a window of 5 ) were removed at Genoinseq, using PRINSEQ v.0.20.4 (Schmieder and Edwards, 2011). Both the high-throughput sequencing procedures and the pre-processing of the reads were carried out at Genoinseq (Biocant, Cantanhede, Portugal).

De-multiplexing, sequencing filtering and processing, and OTU clustering (97\% of similarity) were performed simultaneously as described in Fais et al. (2020), following customized operative procedures in mothur v.1.39.5 (Kozich et al., 2013; Schloss et al., 2009). The Basic Local Alignment Search Tool (BLAST) v.2.6.0 (Benson et al., 2018; last access: April 2019) were processed in GNU Parallel (Tange, 2011; last access: April 2019) with e-value 1e-30, -max_target_seqs 50, -perc_identity 70 settings. The taxonomic assignment to the lowest possible rank of the representative sequences of each OTU (i.e., sequences within the distance threshold defined for each OTU centroid in each dataset; He et al., 2015; Rognes et al., 2016) was run on the MEtaGenome ANalyzer (MEGAN) v.6.13.1 (Huson et al., 2016), as described in Fais et al. (2020). Taxonomic attributions to intermediate ranks (e.g., infraclass, infraorders, suborders and/or lack of specific rank) were assigned to the taxonomic level immediately above. Only the OTUs assigned to the meiofauna sensu Giere (2009) were used in the subsequent phases of the analysis

(namely, taxonomic composition of the community and OTU network analysis). The final OTU tables for the COI and the $18 \mathrm{~S}$ have been designed in Microsoft ${ }^{\circledR}$ Excel $^{\circledR}$ to display both the correct taxonomic attribution of each single OTU/representative sequence and the number of sequences within each OTU for each data set.

Raw sequences without barcodes/adapters are available on the Sequence Read Archive (SRA) of NCBI (https://www.ncbi. nlm.nih.gov/sra/), in the BioProject PRJNA611064, under the accession numbers SAMN14331043 and SAMN14331044 (for the COI and 18S samples of 2017, respectively), and the accession numbers SAMN14944165 and SAMN14944245 (for the COI and 18 Samples of 2018 , respectively).

\subsection{Meiofaunal taxonomic diversity}

Rarefaction and accumulation curves for OTUs assigned to meiofauna were generated using the vegan package (Oksanen et al., 2013) implemented in R (R. Development Core Team, 2018; www.r-project.org), to verify the success of the sequencing depth in representing sample diversity and the number of samples used in representing community diversity. OTU richness was calculated for each sampling station in each year as the accumulated number of the three replicates within each station, for COI and V4.

OTU tables were first optimized to avoid possible biases associated with unequal sequencing effort among samples and artefacts introduced in PCR and sequencing processes, as well as interspecific variation in the intra-genomic copy number of barcoding regions (Toju, 2015). Sequencing reads were then rarefied to a subsampling size corresponding to the smallest number of total reads in the original sample-level matrix, to equalize sequencing effort among samples so as to take into account samples with varying total read counts. Data were finally converted in binary sample-levels matrices (0/1) representing the presence/absence of each OTU attributed to meiofauna on each sampling point.

Beta diversity was used to test for differences between sampling stations along the estuarine gradient. Besides quantifying the compositional difference of biological communities, beta diversity can be partitioned into different components, useful to disentangle the mechanisms involved in diversity patterns. Different approaches have been proposed, mainly based on measures incorporating species replacement and richness differences between communities, or by considering a special case of species richness difference, that is, nestedness (Baselga, 2010, 2012). Nestedness refers to a peculiar pattern characterized by an ordered difference of species richness without replacement, where poorest sites are strict subsets of the richest sites (i.e. richest sites have unique species not present in poorest sites). However, nestedness may ignore the real differences in species richness (Carvalho et al., 2012), accounting for differences only when sites are nested (i.e. sites have at least one common species) and overestimating the replacement component (Tuomisto, 2010). Therefore, a measure able to take into account all richness differences between sampled communities (independently of whether they are nested or not) has been used, by partitioning the total beta diversity $\left(\beta_{\text {tot }}\right)$ into species replacement $\left(\beta_{\text {rep }}\right)$ and richness difference ( $\beta_{\text {rich }}$; Carvalho et al., 2012). The function beta.multi in the BAT (Cardoso et al., 2015) package of $\mathrm{R}$ (R. Development Core Team, 2018; www.r-project.org) was used to quantify the relative contribution of OTU replacement and richness between the sampling stations in different years, by using the Jaccard distance on the presence/absence OTU tables.

For each marker used (COI and 18S) and year (2017 and 2018), a Principal Coordinate Analysis (PCoA) was performed to visualize the degree of dissimilarity between pairs of stations by using the Jaccard distance and the envfit function in the vegan package of $\mathrm{R}$ was used to fit environmental variables on the ordination pattern, assessing the significance of fitted variables $(\mathrm{p}<0.05)$ by means of $n=1,000$ permutations.

Finally, to assess the correlation in the dissimilarity pattern between sampling stations in different years, comparative (Manteltype) tests were used based on the Jaccard dissimilarity matrices. The same tests were performed to assess the patterns produced in metabarcoded datasets using the two different loci.

\subsection{Metabarcoding data network inference and structure}

OTUs co-occurrence networks were built for each sampling station and year from two OTUs tables derived from the use of different markers (COI and 18S). Here, a probabilistic co-occurrence analysis was used to quantify the likelihood of co-occurrences between each pairwise combination of OTUs (Veech, 2013). Differently from other traditional methods based on data randomization, the probabilistic approach has the advantage of having low Type I (false positive) and II (false negatives) error rates (Veech, 
2013). The model provides, analytically, the probability that two selected OTUs co-occur at a frequency either less or higher than an expected frequency of co-occurrence, measured on a random and independent distribution between pairs of OTUs. This probability, with a significance level $\alpha=0.05$, can be used to determine the number of significant positive and negative links between OTUs, measured by a standardized effect size lying between +1 (complete positive association-aggregation) and -1 (complete negative association-segregation).

A series of complementary and universal network metrics were used to test for differences in the pattern of OTUs aggregation/segregation between sampling stations, years and primers. First, the number of co-occurring OTUs $(n)$ has been derived as a surrogate measure of richness, since the final number of OTUs in a network may deviate from the starting sample-level matrix due to non-significant association between pairs during inference. Then, the total number of both positive and negative associations ( $l$ ) and the linkage density $(L D=l / n)$, the average number of positive/negative associations per OTU, were quantified. Finally, modularity $(Q)$, a widely used metric able to measure the degree to which a network can be subdivided in aggregated sets of nodes (i.e., modules) where the within-module links are significantly higher than between-module ones (Newman and Girvan, 2004) was calculated. From an ecological point of view, modularity provides a formal description of the pattern of co-occurrence, where high values correspond to a clear subdivision of the network in distinct group of aggregated/segregated OTUs (Bellisario et al., 2019). Modularity was measured by using a fast approximation of the Newman's algorithm (2004) based on heuristic modular optimization (Blondel et al., 2008) and networks with modularity values of $Q>0.4$ were considered as having a modular structure (Newman, 2004).

Finally, a nonparametric three-way ANOVA based on aligned rank transform (ART, Wobbrock et al., 2011) was finally used to test for the effect of fixed factors (years, sampling stations, primers and the interaction between stations and years) on network metrics.

\section{Results}

Among all measured environmental parameters, salinity was the only showing a significant difference between years and between different sampling stations $(F>40, p<0.001$, for both factors), with average low values in 2018 and, as expected, increasing values moving from inland to the coast.

\subsection{High throughput sequencing data}

A total of 943,334 (COI) and 871,585 (18S) sequences were produced following the de-multiplexing and combination of the pair-end reads. After all filtering processes, 368,472 (COI) and 405,740 (18S) of processed sequences have been BLASTed and clustered in 436 and 555 OTUs, respectively.

For COI, 433 OTUs were assigned among the Eukarya domain: 137 to Animalia, 96 to Chromista, 15 to Protozoa, 7 to Fungi, 5 to Plantae and 174 to unknown eukaryotes. For 18S, 140 OTUs were assigned to Animalia, 172 to Chromista, 4 to Protozoa, 9 to Fungi, 17 to Plantae and 212 to unknown eukaryotes, for a total of 554 OTUs within the Eukarya domain (Supplementary Material, Tables S4 and S5).

OTUs attributed to meiofauna, sensu Giere (2009), were in total 66 for COI (53 Animalia and 13 Protozoa) and 164 for $18 \mathrm{~S}$ (126 Animalia, 35 Chromista and 3 Protozoa).

Rarefaction curves of OTUs attributed to meiofauna reached the saturation at 253 OTUs and 1,431 OTUs, for COI and 18S, respectively (Supplementary Material, Figure S2). Accumulation curves did not display sufficient saturation to explain the whole diversity within the community (Supplementary Material, Figure S3).
Table 1

Results of the beta-diversity partitioning measured as the average or variance of all pairwise values. $\beta_{\text {Tot }}$, total beta-diversity; $\beta_{\text {Rep }}$, beta diversity explained by replacement of OTU alone; $\beta_{\text {Rich, }}$, beta diversity explained by OTU loss/gain (richness differences) alone. Numbers in parentheses are the variance after resampling $(n=100)$.

\begin{tabular}{llll}
\hline Primer (Year) & $\beta_{\text {Tot }}$ & $\beta_{\text {Rep }}$ & $\beta_{\text {Rich }}$ \\
\hline COI (2017) & $0.836( \pm 0.0156)$ & $0.583( \pm 0.0108)$ & $0.253( \pm 0.005)$ \\
COI (2018) & $0.792( \pm 0.0176)$ & $0.444( \pm 0.009)$ & $0.348( \pm 0.007)$ \\
18S (2017) & $0.877( \pm 0.0157)$ & $0.616( \pm 0.0108)$ & $0.272( \pm 0.005)$ \\
$18 S(2018)$ & $0.808( \pm 0.0179)$ & $0.468( \pm 0.001)$ & $0.341( \pm 0.007)$ \\
\hline
\end{tabular}

\subsection{Taxonomic composition of meiofaunal community}

In general, nematodes were the dominant group in all the stations, for each locus and sampling year. Other dominant groups were crustaceans, amoebozoans and annelids for COI, and platyhelminths, ciliophorans and crustaceans for the $18 \mathrm{~S}$ (Fig. 1). Some taxa were exclusively detected by only one marker locus. For example: Cnidaria, Spionida (Nematoda), Terebellida (Nematoda), Tricladida (Platyhelminthes) were detected only by COI; Bryozoa, Gnathostomulida, Ciliophora, Heliozoa, Enchytraeida (Annelida), Phyllodocida (Anellida), Cyclopoida (Crustacea), Araeolaimida (Nematoda), Plectida (Nematoda), Macrostomorpha (Platyhelminthes), Prolecithophora (Platyhelminthes) and Proseriata (Platyhelminthes) by $18 \mathrm{~S}$ (Fig. 1; Supplementary Material, Table S6).

Harpacticoida, Plectida, Enoplida and Enchytraeida were present more or less in all sampling stations and years (Supplementary Material, Table S6), while other taxonomic groups had a more sporadic presence: Bryozoa were detected only at SER station in 2018; Cnidaria at SER in 2017 and at POR and SER in 2018; Gnathostomulida at MEA station in both years; Heliozoa at POR station (Fig. 1).

\subsection{Community composition and beta diversity}

Temporal comparison indicated a very similar number of total OTUs recovered by using different primers (60 versus 55 OTUs, for COI, and 147 versus 140 OTUs, for 18S, in 2017 and 2018, respectively; Fig. 2), showing, overall, a high percentage of shared OTUs between years (approximately $75 \%$ for both marker loci, Fig. 2). Within each year, a very low percentage of shared OTUs among all sampling stations was found, in a percentage varying between approximately 6 to 11\% (Fig. 3). Within each station, the $\%$ of shared OTUs between years was slightly higher and varied between apporximately 32 and $62 \%$, for COI, and 34 and 51\%, for $18 \mathrm{~S}$ (Fig. 2). This pattern was confirmed by the ordination of sampled communities provided by the PCoA showing that the structure and composition of metabarcoded communities was not influenced by the use of different primers, although differences were found between years (Fig. 4). These results suggest a high degree of spatial turnover both within and between sampling stations. Consequently, most of the beta-diversity was accounted by OTU replacement with only a minor contribution from OTU richness (Table 1). No correlation was found between communities' composition in different years regardless of the primer used (Mantel test, $p>0.7$ for both primers), although a significant correlation was observed between $\mathrm{COI}$ and $18 \mathrm{~S}$ within the same years (Mantel test, $p<0.01$ ).

\subsection{Network analysis}

None of the network metrics differed between used primers, meaning that association networks showed invariant properties despite the strong differences in OTU delimitation provided by 


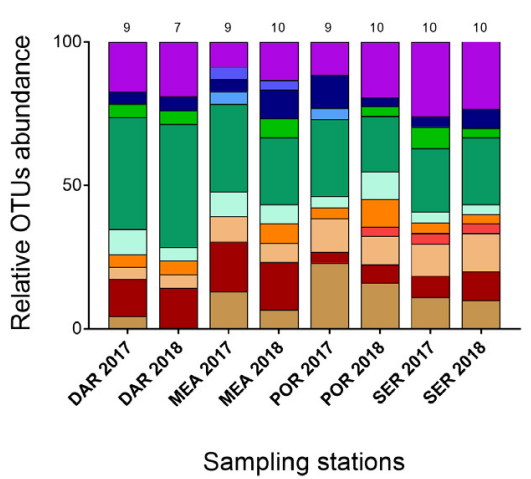

B.

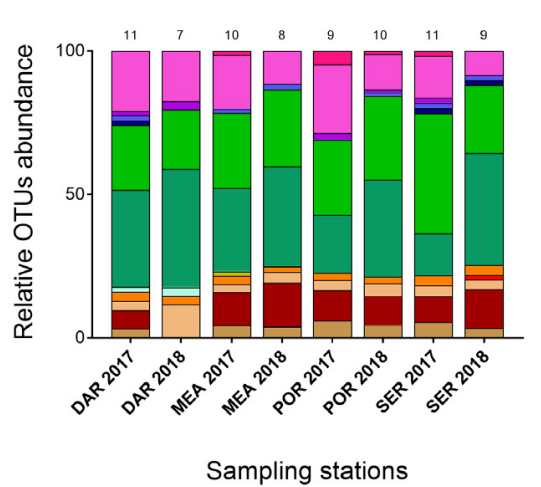

$\square$ Heliozoa

$\square$ Ciliophora

Amoebozoa

$\square$ Xenacoelomorpha

Porifera

- Rotifera

Platyhelminthes

- Nematoda

$\square$ Mollusca

Gnathostomulida

$\square$ Gastrotricha

Cnidaria

- Bryozoa

$\square$ Trombidiformes

- Crustacea

$\square$ Annelida

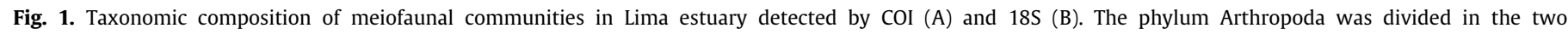

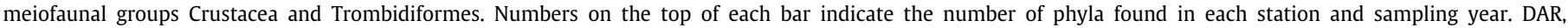
Darque; MEA, Meadela; POR, Santa Marta de Portuzelo; SER, Serreleis.

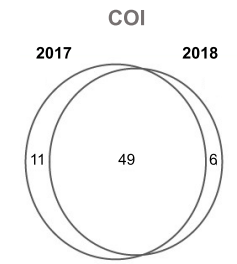

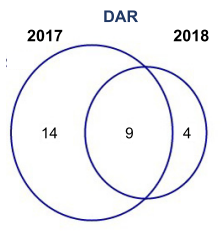

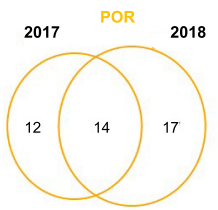

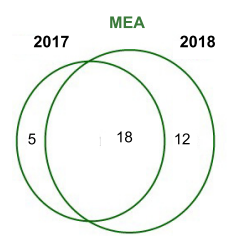

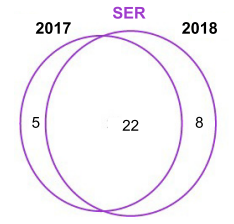

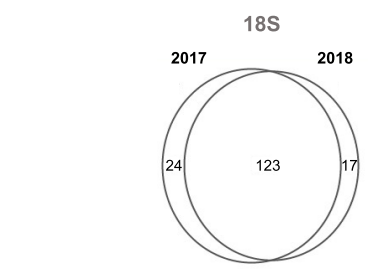
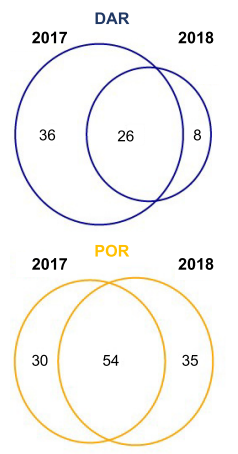
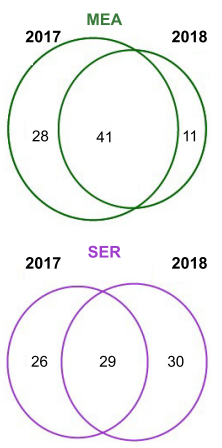

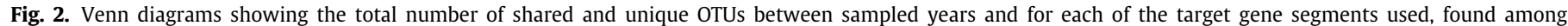

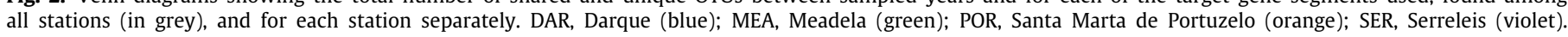

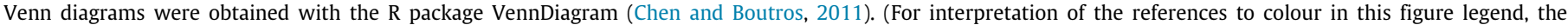
reader is referred to the web version of this article.)

COI and 18S. Although an increasing number of co-occurring OTUs can be observed moving from the coast to the inland (Fig. 5), none of the main factors and their interaction provided statistical support for significant differences. The number of positive associations significantly differed between sampling stations $(F>8.4$, $p<0.011, d f=3$ ), suggesting an increasing pattern of aggregation (i.e., positive linkage density) moving from the coast to inland (Fig. 5). The total number of negative associations and connectedness (i.e., negative linkage density) did not show any significant spatial or temporal difference ( $F<1.08, p>0.2$ in both cases), although a year-to-year variation within sampling stations can be observed ( $F>5.148, p<0.034, d f=3$ for both parameters), decreasing in stations closest to the coast. Overall, modularity differed between stations ( $F=14.471, p=0.002, d f=3)$ and within stations in different years $(F=22.488, p<0.001, d f=3)$, suggesting an increasing modular structure moving from inland to coastal stations in 2017 with no significant differences in 2018.

\section{Discussion}

In this study, the usefulness of integrating eDNA metabarcoding and s network ecology analysis was demonstrated to provide evidences of peculiar patterns in meiofaunal community composition, otherwise difficult to detect with current analytical frameworks. Despite the limited spatial and temporal extension of the study, relatively stable properties of meiofaunal communities in terms of taxonomic composition, dissimilarity (i.e., beta diversity) and specific network feautures were found. Overall, it has been demonstrated how both the taxonomic replacement of OTUs and their associations (e.g., positive vs. negative segregation) are the main mechanisms structuring meiofaunal communities along the Lima estuary gradient.

The introduction of DNA-based methods is highlighting the narrow range distribution of some species complexes (Bhadury et al., 2006a,b; Markmann and Tautz, 2005; Pawlowski et al., 1994) and allowing to identify important taxa within meiofauna (Giere, 2009). Additionally, the application of DNA metabarcoding for assessing meiofauna at different spatial scales and in different environments is making possible further clarifications on the ecology of this community (Fais et al., 2020; Fonseca et al., 2014, 2017; Lallias et al., 2015) and temporal dynamics (Guardiola et al., 2016).

Although we are still far from using an harmonized DNA metabarcoding approach to respond ecological issues (Zinger 

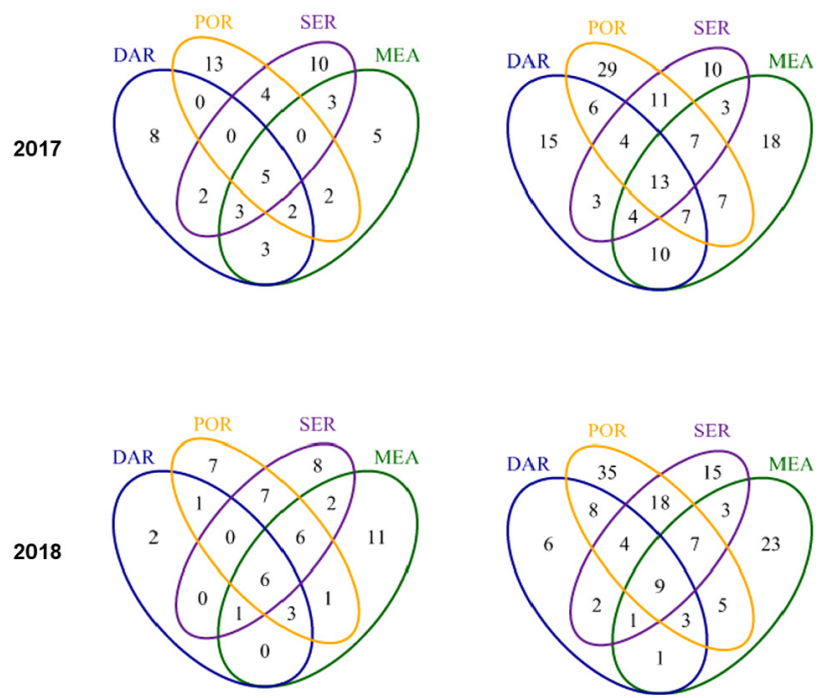

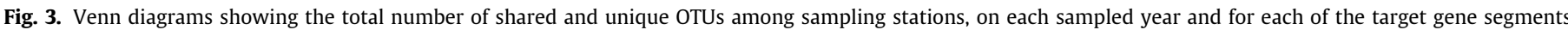

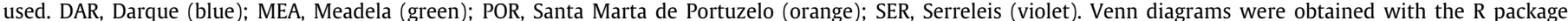

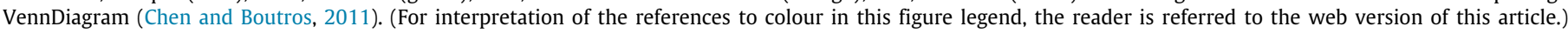
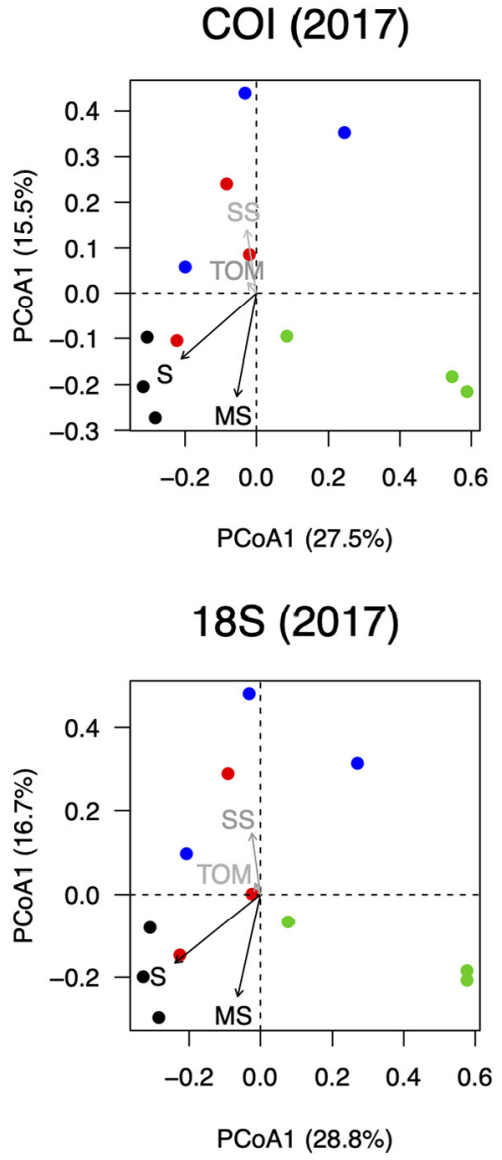
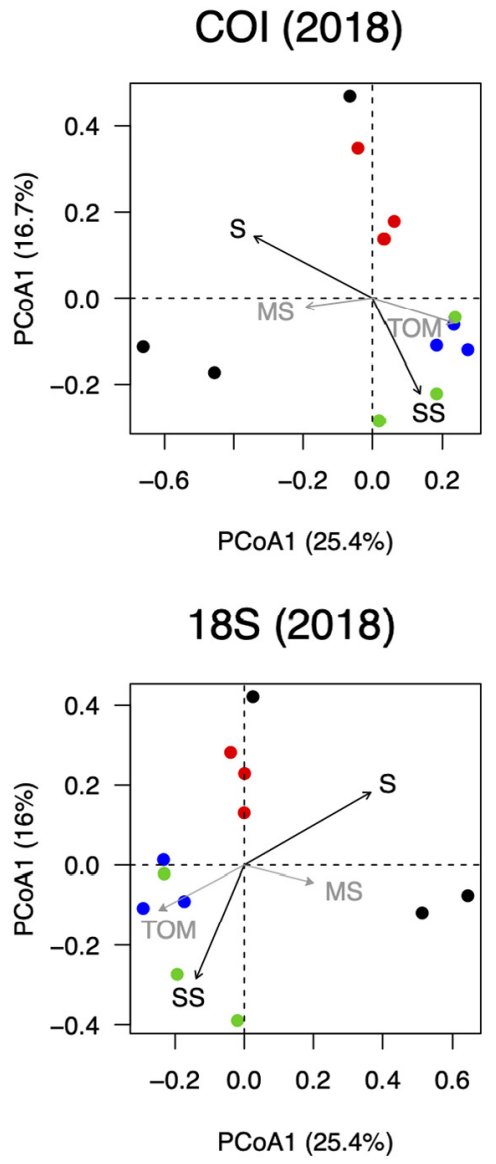

\section{Sampling stations $\bullet$ DAR $\bullet$ MEA $\odot$ POR $\bullet$ SER}

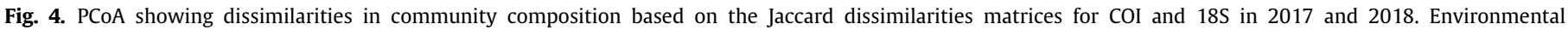
variables were superimposed on the ordination, with black and grey arrows showing significant $(p<0.05)$ and not significant $(p>0.05)$ fits, respectively. 


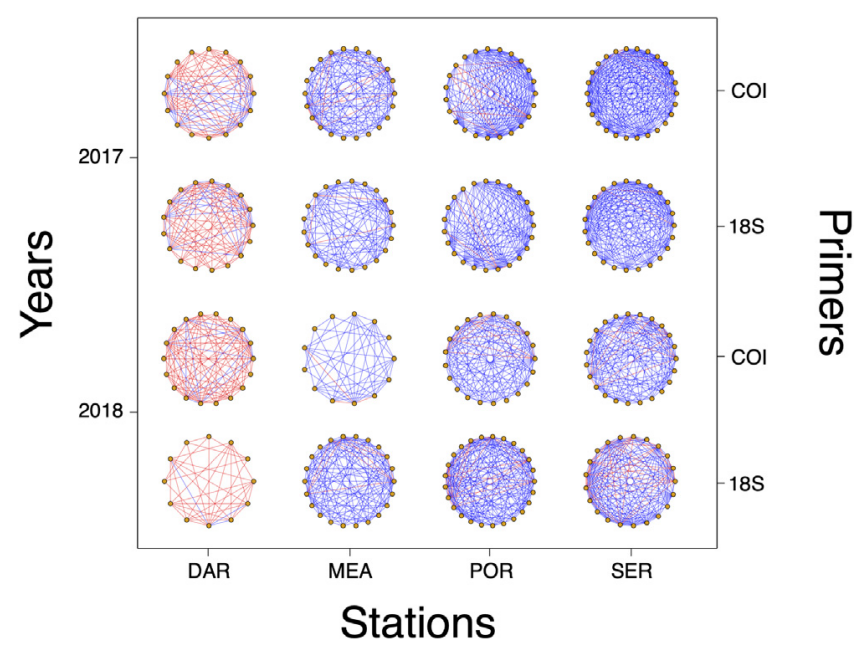

Fig. 5. Inferred association networks of meiofaunal OTUs. Networks are visualized on a three-axes plot showing the sampling stations, years and primer used. Red and blue lines are for significant negative (segregation) and positive (aggregation) associations, respectively. (For interpretation of the references to colour in this figure legend, the reader is referred to the web version of this article.)

et al., 2019), numerous progresses have been made in optimizing procedures according to the communities of interest (PavanKumar et al., 2015; Creer et al., 2016). In a previous study on Lima estuary, it was demonstrated how OTUs attributed to meiofauna displayed a high turnover between sampling points a few metres apart (Fais et al., 2020). The characterization of the community was possible using 6 sampling units at each site, thus differentiating each of them on a small-spatial scale; however, with only 3 samples it was possible to attain approximately $85 \%$ of the total OTUs diversity of the intertidal meiofauna in Lima estuary (Fais et al., 2020). Moreover, previous investigations through DNA metabarcoding have demonstrated the importance of a multi-locus approach and sample's size for monitoring meiofauna in marine-coastal environments, focusing on small-scale spatial variation (Brannock and Halanych, 2015; Cowart et al., 2015; Haenel et al., 2017; Nascimento et al., 2018; Cordier et al., 2019; Fais et al., 2020).

In the present study, sample diversity of intertidal meiofauna was thoroughly assessed, as demonstrated by the achievement of saturation in the rarefaction curves. Conversely, diversity of the intertidal community was not sufficiently expressed, limiting observations by around $15 \%$, as shown from accumulation curves still growing and in comparison to a previous study (Fais et al., 2020). Nevertheless, this restraint was overcome by the number of amplicon libraries produced ( 8 per station), which accurately captures a broader range of phylogenetic diversity of intertidal communities in Lima estuary. In terms of OTUs richness and taxonomic composition, the use of two different molecular markers [i.e., a portion of the cytochrome oxidase I (COI) and a hypervariable region of the $18 \mathrm{~S} \mathrm{rDNA}]$, provided interesting evidences. On the one hand, the higher OTU richness within the $18 \mathrm{~S}$ compared to the COI marker; on the other, the exclusive or preferential detection of particular taxa by one of them in different levels of taxonomic identification. Despite the lack of specific reference libraries in public databases (Tang et al., 2012; Weigand et al., 2019), it was possible to detect different predominant taxa (platyhelminths, amoebozoans and ciliophorans) in addition to nematodes and some others taxa (e.g., annelids, crustaceans, gastrotrichs and mites) recurring in all stations, suggesting that some taxonomic groups may play an important role on community's structure. At a lower taxonomic level, rhabdocoels (within platyhelminths) were more numerous than nematode's taxa; furthermore, a high variability of different orders was detected among the stations and years of sampling. Hence, from a qualitative point of view, the community was variable in response to the environmental conditions at a smallscale spatial variation. For example, triclades were present in freshwater areas (POR-SER), and macrostomorphs and cyclopoids were present in fine sands or muddy sediments. On the contrary, harpacticoids were found in all the stations, probably to their dispersal and rapid recolonization abilities (Giere, 2009 and references therein). However, the taxonomic composition of communities, in terms of relative proportion and occurrence of phyla or sub-phyla in each station, appears to be fairly similar between years.

Globally, intertidal meiofaunal communities in Lima estuary were characterized mainly by marine-origin taxa, which could be stressed by oligo- or mesohaline conditions, reflecting some aspects already encountered for the macrobenthos of the same area (Sousa et al., 2006). In such situations, the marine meiofauna could have undergone a great adaptive effort, while the limnetic meiofauna would have found more favourable conditions for survival (Santos et al., 1996; Alves et al., 2015; Smyth and Elliot, 2016). Indeed, limnetic meiofauna may survive in more unstable conditions, thanks to the persistence of quiescent stages (resting eggs, cysts or cryptobiotic adults), which seem to be less frequent in marine meiobenthos (Worsaee et al., 2019). Furthermore, some taxonomic groups of limnetic meiofauna may reach easily the coastal areas by the passive erosion and sediment transportation downstream (Giere, 2009 and references therein), above all in 2018, when a higher precipitation was recorded in Northern Portugal in comparison to the previous year (https://www.pordata. pt/en/Home).

These results were also confirmed by the network structures of co-occurring OTUs, which indicated mainly the existence of relatively stable properties, irrespective of years and the high levels of replacement detected by using the two genetic markers (COI and 18S). Network properties appeared to shift sharply from the downstream/high salinity end of the estuary to the mesohaline medium-upstream areas of the estuary, reinforcing the idea that meiofaunal communities are characterized by redundancy with dominance of taxa-specific traits and life-history characteristics able to cope with different environmental conditions (e.g., salinity, granulometry) along the estuarine gradient (Lallias et al., 2015). This community-level pattern may have influenced the degree to which OTUs aggregate, leading for an increasing segregation (i.e., negative association) of close-relative taxa characterized by similar responses to environmental conditions. Thereby, despite the high changes observed in the fine taxonomic hierarchies (i.e., species-level, assuming OTUs as species proxies), the relative proportions of higher taxonomic ranks indicated considerable stability in the meiofaunal communities' composition. The lack of a significant temporal difference in both beta-diversity and network features indicates that meiofaunal communities are more affected by spatial rather than temporal variation, similarly to previous findings where spatial variability overrode temporal changes in determining community composition of meiofauna (Sun et al., 2017).

These results suggested that meiofaunal community composition appeared to have a dual nature: on one side there were numerous elements characterized by a sparse occurrence that contribute to an exceptionally high level of spatial variation in meiofauna's OTUs, as suggested earlier in previous studies either through classical (Alves et al., 2009) or metabarcoding (Fais et al., 2020; Lallias et al., 2015; Nascimento et al., 2018) approaches. On the other side, there were aspects of the community that appear to remain relatively constant (i.e., proportion of taxonomic 
groups), or that can be associated with particular sites and environmental conditions (e.g., salinity and sediment features). For instance, small benthic metazoans tend to cluster in microsites rich in organic matter content (Giere, 2009; Nascimento et al., 2008) and salinity has been also found as a main factor structuring meiofaunal communities in marine environments (Alves et al., 2009; Lallias et al., 2015; Fais et al., 2020; Sun et al., 2017).

Disentangling the components of beta-diversity allowed for a more comprehensive understanding of the mechanisms driving the observed diversity pattern (Baselga, 2010; Carvalho et al., 2012; Legendre, 2014), showing the predominant role of replacement in explaining changes in community composition, a pattern that was consistent in the two years of sampling. Here, the key role played by replacement can be interpreted as a consequence of the strong environmental filtering acting at different spatial scales (Hill et al., 2019), although other mechanisms cannot be neglected (e.g., competition, historical events and evolutionary history; Leprieur et al., 2011). The contribution of OTUs replacement to beta-diversity was consistent and very high, either between sampling points only four to five metres apart, as well as among sampling stations along the estuary. Although salinity was found to be the main parameter able to discriminate the sampling stations over large scale (i.e., estuary scale), fine-scale environmental filtering may have contributed to this pattern (Alves et al., 2009; Lallias et al., 2015; Fais et al., 2020; Sun et al., 2017), suggesting that beta-diversity in meiofaunal communities may depended on taxa-specific traits. These findings were consistent with the results obtained by analysing the network association pattern of OTUs attributed to meiofauna within sampling stations.

Despite the high degree of replacement, association networks were characterized by relatively stable properties, suggesting that changes in meiofaunal community composition (even at finespatial scale) were not associated with changes in network structure, showing parallel responses of OTUs to environmental filtering. Our analysis also revealed a high 'fidelity' in the pattern of OTUs association, with increasing negative associations (i.e., segregation) of OTUs and modularity moving from the inland to the coast, independently of both primers and years of sampling. The sampling station closer to the ocean, thereby with the highest salinity regime (DAR), outstand compared to the three remaining mesohaline stations spanning the mid-lower estuary. Co-occurrence networks were clearly dominated by negative associations and high modularity in DAR, shifting sharply (and significantly) to clearly positive-dominated associations and low modularity in the remaining stations. This pattern may be an outcome of non-overlapping habitat requirements along the Lima estuary, leading for differences in the spatial distribution of OTUs. This shift can be related with the opportunistic colonization by truly marine species, which however were able to disperse further upstream into the estuary, although the probability to establish in non-suitable environments (i.e., mesohaline mediumupstream areas) decreases with the increasing distance from the coast. Therefore, the observed pattern of OTUs co-occurrence was likely to be determined by the degree of environmental heterogeneity within and between sampling stations, leading to niche differentiation and, consequently, to segregated and clustered (i.e., modular) co-occurrence patterns.

The relatively stable network properties and association 'fidelity' patterns in space and time may indicate the replacement of topologically similar OTUs, suggesting high taxonomic and/or functional redundancy in meiofaunal communities (Rosenfeld, 2002). Thus, the wide replacement of species may not necessarily compromise the functional performance of the community as a whole (Cardinale et al., 2012). Relevant implications can be derived for meiofauna-based environmental monitoring of estuaries. Viewed from a species (or OTU) composition perspective, the presence of a high portion of variable components in these communities made it harder to associate particular taxa with specific environmental conditions, be it more disturbed or pristine, a task that is more complex at start in a community whose taxonomic knowledge is still very incipient (Fonseca et al., 2017; Fontaneto et al., 2015; Giere, 2009). On the other hand, if certain network properties are inherent features of these communities, they could be linked with environmental settings regardless of the species composition, serving as a yardstick to detect departures from expected properties that signal more insidious environmental disturbances.

\section{Conclusions}

As much as we are aware of the limited spatial and temporal survey dimension, this study is the first attempt to assess intertidal meiofauna under an integrated approach, showing the usefulness of merging DNA metabarcoding with network analysis to highlight the peculiar characteristics of intertidal meiobenthos and emphasizing its importance in environmental monitoring strategies. Overall, our results suggest that the examination of the network features in meiofauna may help understanding the ecology and dynamics of these communities that apparently hold large portions of variable elements, thereby making difficult their analyses solely based on the OTU/species composition. For instance, seasonal changes in species interactions can modulate the effect of differences in species composition on the likelihood of persistence in meiofaunal communities across the year, a situation which is likely to occur in extremely dynamic systems as estuaries and intertidal zones. This raises a number of questions about how temporal and spatial changes in the pattern of associations should generate different consequences on the functioning of those systems. Our results corroborate the hypothesis that more efficient biodiversity surveys should keep pace with advances in eDNA protocols and novel analytical frameworks, to better understand the mechanisms and dynamics of community assembly processes, as well as their implications for ecosystem functioning. Ongoing studies are now assessing whether these findings can be extended to other estuarine systems.

\section{CRediT authorship contribution statement}

Maria Fais: Conceptualization, Methodology, Software, Validation, Formal analysis, Investigation, Data curation, Writing original draft, Writing - review \& editing, Visualization. Bruno Bellisario: Conceptualization, Software, Validation, Formal analysis, Investigation, Writing - original draft, Writing - review \& editing, Visualization. Sofia Duarte: Conceptualization, Methodology, Formal analysis, Investigation, Resources, Writing - original draft, Writing - review \& editing, Visualization. Pedro Emanuel Vieira: Conceptualization, Validation, Formal analysis, Writing - review \& editing, Visualization. Ronaldo Sousa: Writing - review \& editing, Visualization, Supervision. Carlos Canchaya: Conceptualization, Methodology, Software, Validation, Formal analysis, Data curation, Writing - review \& editing, Visualization, Supervision. Filipe Oliveira Costa: Conceptualization, Funding acquisition, Methodology, Resources, Supervision, Validation, Visualization, Writing original draft, Writing - review \& editing.

\section{Declaration of competing interest}

The authors declare that they have no known competing financial interests or personal relationships that could have appeared to influence the work reported in this paper. 


\section{Acknowledgements}

This study was funded by the project "The NextSea: Next generation monitoring of coastal ecosystems in a scenario of global change" (operação NORTE-01-0145-FEDER-000032), supported by Norte Portugal Regional Operational Programme (NORTE 2020), under the PORTUGAL 2020 Partnership Agreement, through the European Regional Development Fund (ERDF). Maria Fais and Sofia Duarte were supported, respectively by a Ph.D. (SFRH/BD/113547/2015) and a post-doc fellowship (SFRH/BPD/109842/2015) from FCT. The authors would like to thank Prof. Jesús Troncoso (University of Vigo) and Prof. Pedro Gomes (University of Minho) for their availability and hospitality for the lab processing; Dr. Bruno Sampieri and Barbara Leite (University of Minho) for the great support during the implementation of the practical stage of the research. The authors would like also to thank the anonymous reviewers for critically reading the manuscript and suggesting substantial improvements.

\section{Appendix A. Supplementary data}

Details on environmental variables and description of primerpairs, limited-cycle PCR and OTUs tables with the lowest taxonomic assignments attributed to meiofauna, for both molecular markers used, can be found online at https://doi.org/10.1016/j. rsma.2020.101341.

\section{References}

Alves, A.S., Adão, H., Patrício, J., Neto, J.M., Costa, M.J., Marques, J.C., 2009. Spatial distribution of subtidal meiobenthos along estuarine gradients in two southern European estuaries (Portugal). Acta Oecologica 35, 287-300. http://dx.doi.org/10.1016/j.actao.2008.11.007.

Alves, A.S., Caetano, A., Costa, J.L., Costa, M.J., Marques, J.C., 2015. Estuarine intertidal meiofauna and nematode communities as indicator of ecosystem's recovery following mitigation measures. Ecol. Indic. 54, 184-196. http://dx. doi.org/10.1016/j.ecolind.2015.02.013.

Andújar, C., Arribas, P., Yu, D.W., Vogler, A.P., Emerson, B.C., 2018. Why the COI barcode should be the community DNA metabarcode for the Metazoa. Mol. Ecol. 396, 8-3975. http://dx.doi.org/10.1111/mec.14844.

Baselga, A., 2010. Partitioning the turnover and nestedness components of beta diversity. Glob. Ecol. Biogeogr. 19, 134-143. http://dx.doi.org/10.1111/j.14668238.2009.00490.x.

Baselga, A., 2012. The relationship between species replacement, dissimilarity derived from nestedness, and nestedness. Glob. Ecol. Biogeogr. 21, 1223-1232. http://dx.doi.org/10.1111/j.1466-8238.2011.00756.x.

Bellisario, B., Camisa, F., Abbattista, C., Cimmaruta, R., 2019. A network approach to identify bioregions in the distribution of Mediterranean amphipods associated with Posidonia oceanica meadows. PeerJ 7, e6786. http://dx.doi. org/10.7717/peerj.6786.

Benson, D.A., Cavanaugh, M., Clark, K., Karsch-Mizrachi, I., Ostell, J., Pruitt, K.D., Sayers, E.W., 2018. Genbank. Nucleic Acids Res. 46, D41-D47. http://dx.doi. org/10.1093/nar/gkx1094.

Bhadury, P., Austen, M.C., Biltonm, D.T., Lambshead, P.J.D., Rogers, A.D., Smerdon, G.R., 2006a. Development and evaluation of a DNA-barcoding approach for the rapid identification of nematodes. Mar. Ecol. Prog. Ser. 320, 1-9. http://dx.doi.org/10.3354/meps320001.

Bhadury, P., Austen, M.C., Biltonm, D.T., Lambshead, P.J.D., Rogers, A.D., Smerdon, G.R., 2006b. Molecular detection of marine nematodes from environmental samples: overcoming eukaryotic interference. Aquat. Microbiol. Ecol. 44, 97-103. http://dx.doi.org/10.3354/ame044097.

Bik, H.M., Porazinska, D.L., Creer, S., Caporaso, J.G., Knight, R., Thomas, W.K., 2012. Sequencing our way towards understanding global eukaryotic biodiversity. Trends Ecol. Evol. 27 (4), 233-243. http://dx.doi.org/10.1016/j.tree.2011.11. 010.

Blondel, V.D., Guillaume, J.L., Lambiotte, R., Lefebvre, E., 2008. Fast unfolding of communities in large networks. J. Stat. Mech. Theory Exp. (10), P10008. http://dx.doi.org/10.1088/1742-5468/2008/10/P10008.

Brannock, P.M., Halanych, K.M., 2015. Meiofaunal community analysis by highthroughput sequencing: Comparison of extraction, quality filtering, and clustering methods. Mar. Genom. 23, 67-75. http://dx.doi.org/10.1016/j. margen.2015.05.007.
Cardinale, B.J., Duffy, J.E., Gonzalez, A., Hooper, D.U., Perrings, C., Venail, P., Narwani, A., MacE, G.M., Tilman, D., Wardle, D.A., Kinzig, A.P., Daily, G.C., Loreau, M., Grace, J.B., Larigauderie, A., Srivastava, D.S., Naeem, S., 2012. Biodiversity loss and its impact on humanity. Nature 486, 59-67. http: //dx.doi.org/10.1038/nature11148.

Cardoso, P., Rigal, F., Carvalho, J.C., 2015. BAT - Biodiversity Assessment Tools, an $\mathrm{R}$ package for the measurement and estimation of alpha and beta taxon, phylogenetic and functional diversity. Methods Ecol. Evol. 6 (2), 232-236. http://dx.doi.org/10.1111/2041-210X.12310.

Carvalho, J.C., Cardoso, P., Gomes, P., 2012. Determining the relative roles of species replacement and species richness differences in generating betadiversity patterns. Glob. Ecol. Biogeogr. 21 (7), 760-771. http://dx.doi.org/ 10.1111/j.1466-8238.2011.00694.x.

Chen, H., Boutros, P.C., 2011. VennDiagram: a package for the generation of highly-customizable Venn and Euler diagrams in R. BMC Bioinform. 12, 35. http://dx.doi.org/10.1186/1471-2105-12-35.

Cordier, T., Frontalini, F., Cermakovac, K., Apothéloz-Perret-Gentila, L., Tregliad, M., Scantamburlod, E., Bonamine, V., Pawlowski, J., 2019. Multi-marker eDNA metabarcoding survey to assess the environmental impact of three offshore gas platforms in the North Adriatic Sea (Italy). Mar. Environ. Res. 146, 24-34. http://dx.doi.org/10.1016/j.marenvres.2018.12.009.

Costa-Dias, S., Sousa, R., Antunes, C., 2010. Ecological quality assessment of the lower Lima Estuary. Mar. Pollut. Bull. 61, 234-239. http://dx.doi.org/10.1016/ j.marpolbul.2010.02.019.

Coull, B.C., 1999. Role of meiofauna in estuarine soft-bottom habitats. Aust. J. Ecol. 24, 327-343. http://dx.doi.org/10.1046/j.1442-9993.1999.00979.x.

Cowart, D.A., Pinheiro, M., Mouchel, O., Maguer, M., Grall, J., Miné, J., ArnaudHaond, S., 2015. Metabarcoding is powerful yet still blind: A comparative analysis of morphological and molecular surveys of seagrass communities. PLoS One 10 (2), e0117562. http://dx.doi.org/10.1371/journal.pone.0117562.

Creer, S., Deiner, K., Frey, S., Porazinska, D., Taberlet, P., Thomas, W.K., Potter, C., Bik, H.M., 2016. The ecologist's field guide to sequence-based identification of biodiversity. Methods Ecol. Evol. 7, 1008-1018. http://dx.doi.org/10.1111/ 2041-210X.12574

Danovaro, R., Gambi, M.C., Mirto, S., Sandulli, R., Ceccherelli, V.U., 2004. Chapter 3. meiofauna. In: Gambi, M.C., Dappiano, M. (Eds.), Mediterranean Marine Benthos: A Manual of Methods for Its Sampling and Study. In: Biologia Marina Mediterranea, vol. 11, pp. 55-97.

Elbrecht, V., Leese, F., 2015. Can DNA-based ecosystem assessments quantify species abundance? Testing primer bias and biomass-sequence relationships with an innovative metabarcoding protocol. PLoS One 10 (7), e0130324. http://dx.doi.org/10.1371/journal.pone.0130324.

Fais, M., Duarte, S., Vieira, P.E., Sousa, R., Hajibabaei, M., Canchaya, C.A., Costa, F.O., 2020. Small-scale spatial variation of meiofaunal communities in lima estuary (NW Portugal) assessed through metabarcoding. Estuar. Coast. Shelf Sci. 106683. http://dx.doi.org/10.1016/J.ECSS.2020.106683.

Fenchel, T., Finlay, B.J., 2004. The ubiquity of small species: Patterns of local and global diversity. Bioscience. Bioscience 54 (8), 777-784. http://dx.doi.org/10. 1641/0006-3568(2004)054[0777:tuossp]2.0.co;2.

Fonseca, V.G., Carvalho, G.R., Nichols, B., Quince, C., Johnson, H.F., Neill, S.P., Lambshead, J.D., Thomas, W.K., Power, D.M., Creer, S., 2014. Metagenetic analysis of patterns of distribution and diversity of marine meiobenthic eukaryotes. Global Eco. Biogeogr. 23, 1293-1302. http://dx.doi.org/10.1111/ geb. 12223.

Fonseca, G., Fontaneto, D., Di Domenico, M., 2017. Addressing biodiversity shortfalls in meiofauna. J. Exp. Mar. Bio. Ecol. 502, 26-38. http://dx.doi.org/ 10.1016/j.jembe.2017.05.007.

Fontaneto, D., Flot, J.F., Tang, C.Q., 2015. Guidelines for DNA taxonomy, with a focus on the meiofauna. Mar. Biodivers. 45, 433-451. http://dx.doi.org/10. 1007/s12526-015-0319-7.

Freilich, M.A., Wieters, E., Broitman, B.R., Marquet, P.A., Navarrete, S.A., 2018. Species co-occurrence networks: Can they reveal trophic and non-trophic interactions in ecological communities? Ecology 99 (3), 690-699. http://dx. doi.org/10.1002/ecy.2142.

Gerlach, S.A., 1971. On the importance of marine meiofauna for benthos communities. Oecologia 6, 176-190. http://dx.doi.org/10.1007/BF00345719.

Gibson, J.F., Stein, E.D., Baird, D.J., Max, F.C., Zhang, X., Hajibabaei, M., 2015. Wetland ecogenomics - the next generation of Wetland biodiversity and functional assessment. Wetl. Sci. Pract. 32, 27-32.

Giere, O., 2009. Meiobenthology: The Microscopic Motile Fauna of Aquatic Sediments, second ed. Springer-Verlag Berlin Heidelberg, http://dx.doi.org/ 10.1007/978-3-540-68661-3.

Guardiola, M., Wangensteen, O.S., Taberlet, P., Coissac, E., Uriz, M.J., Turon, X., 2016. Spatio-temporal monitoring of deep-sea communities using metabarcoding of sediment DNA and RNA. PeerJ 4, e2807. http://dx.doi.org/10.7717/ peerj.2807.

Haenel, Q., Holovachov, O., Jondelius, U., Sundberg, P., Bourlat, S., 2017. NGS-based biodiversity and community structure analysis of meiofaunal eukaryotes in shell sand from Hållö island, Smögen, and soft mud from Gullmarn Fjord, Sweden. Biodivers. Data J. 5, e12731. http://dx.doi.org/10. 3897/BDJ.5.e12731. 
Hajibabaei, M., Spall, J.L., Shokralla, S., Kvan Konynenburg, S., 2012. Assessing biodiversity of a freshwater benthic macroinvertebrate community through non-destructive environmental barcoding of DNA from preservative ethanol. BMC Ecol. 12, 28. http://dx.doi.org/10.1186/1472-6785-12-28.

He, Y., Caporaso, J.G., Jiang, X.T., Sheng, H.F., Huse, S.M., Rideout, J.R., Edgar, R.C., Kopylova, E., Walters, W.A., Knight, R., Zhou, W.H., 2015. Stability of operational taxonomic units: an important but neglected property for analyzing microbial diversity. Microbiome 3, 20. http://dx.doi.org/10.1186/s40168-0150081-X.

Heip, C., Vincx, M., Vranken, G., 1985. The ecology of marine nematodes. Oceanogr. Mar. Biol. Ann. Rev. 23, 399-489.

Hill, M.J., Heino, J., White, J.C., Ryves, D.B., Wood, P.J., 2019. Environmental factors are primary determinants of different facets of pond macroinvertebrate alpha and beta diversity in a human-modified landscape. Biol. Conserv. 237, 348-357. http://dx.doi.org/10.1016/j.biocon.2019.07.015.

Huson, D.H., Beier, S., Flade, I., Górska, A., El-Hadidi, M., Mitra, S., Ruscheweyh, H.J., Tappu, R., 2016. MEGAN Community edition - interactive exploration and analysis of large-scale microbiome sequencing data. PLoS Comput. Biol. 12 (6), e1004957. http://dx.doi.org/10.1371/journal.pcbi. 1004957.

Ilarri, M.I., Souza, A.T., Antunes, C., Guilhermino, L., Sousa, R., 2014. Influence of the Asian clam Corbicula fluminea (Bivalvia: COrbiculidae) on estuarine epibenthic assemblages. Estuar. Coast. Shelf Sci. 143, 12-19. http://dx.doi. org/10.1016/j.ecss.2014.03.017.

Illumina, 2013. 16S Metagenomic sequencing library preparation - preparing 16S ribosomal RNA gene amplicons for the illumina miseq system. 16S metagenomic seq. Libr. Prep. Man. 1-28.

Kozich, J.J., Westcott, S.L., Baxter, N.T., Highlander, S.K., Schloss, P.D., 2013. Development of a dual-index sequencing strategy and curation pipeline for analyzing amplicon sequence data on the miseq illumina sequencing platform. Appl. Environ. Microbiol. 79, 5112-5120. http://dx.doi.org/10.1128/ AEM.01043-13.

Lallias, D., Hiddink, J.G., Fonseca, V.G., Gaspar, J.M., Sung, W., Neill, S.P., Barnes, N., Ferrero, T., Hall, N., Lambshead, P.J.D., Packer, M., Thomas, W.K., Creer, S., 2015. Environmental metabarcoding reveals heterogeneous drivers of microbial eukaryote diversity in contrasting estuarine ecosystems. ISME J. 9 (5), 1208-1221. http://dx.doi.org/10.1038/ismej.2014.213.

Leasi, F., Sevigny, J.L., Laflamme, E.M., Artois, T., Curini-Galletti, M., de Jesus Navarrete, A., Di Domenico, M., Goetz, F., Hall, J.A., Hochberg, R., Jörger, K.M., Jondelius, U., Todaro, M.A., Wirshing, H.H., Norenburg, J.L., Thomas, W.K., 2018. Biodiversity estimates and ecological interpretations of meiofaunal communities are biased by the taxonomic approach. Commun. Biol. 1 (112), 1-10. http://dx.doi.org/10.1038/s42003-018-0119-2.

Legendre, P., 2014. Interpreting the replacement and richness difference components of beta diversity. Glob. Ecol. Biogeogr. 23 (11), 1324-1334. http: //dx.doi.org/10.1111/geb.12207.

Lejzerowicz, F., Esling, P., Pillet, L., Wilding, T.A., 2015. High-throughput sequencing and morphology perform equally well for benthic monitoring of marine ecosystems. Sci. Rep. 5, 13932. http://dx.doi.org/10.1038/srep13932.

Leprieur, F., Tedesco, P.A., Hugueny, B., Beauchard, O., Dürr, H.H., Brosse, S., Oberdorff, T., 2011. Partitioning global patterns of freshwater fish beta diversity reveals contrasting signatures of past climate changes. Ecol. Lett. 14 (4), 325-334. http://dx.doi.org/10.1111/j.1461-0248.2011.01589.x.

Leray, M., Yang, J.Y., Meyer, C.P., Mills, S.C., Agudelo, N., Ranwez, V., Boehm, J.T., Machida, R.J., 2013. A new versatile primer set targeting a short fragment of the mitochondrial COI region for metabarcoding metazoan diversity: Application for characterizing coral reef fish gut contents. Front. Zool. 10 (34), 1-14. http://dx.doi.org/10.1186/1742-9994-10-34.

Lobo, J., Costa, P.M., Teixeira, M.A.L., Ferreira, M.S.G., Costa, M.H., Costa, F.O., 2013. Enhanced primers for amplification of DNA barcodes from a broad range of marine metazoans. BMC Ecol. 13, 1. http://dx.doi.org/10.1186/14726785-13-34.

Markmann, M., Tautz, D., 2005. Reverse taxonomy: an approach towards determining the diversity of meiobenthic organisms based on ribosomal RNA signature sequences. Phil. Trans. R. Soc. B Biol. Sci. 360, 1917-1924. http: //dx.doi.org/10.1098/rstb.2005.1723.

McGee, K.M., Robinson, C.V., Hajibabaei, M., 2019. Gaps in DNA-based biomonitoring across the globe. Front. Ecol. Evol. 7, 337. http://dx.doi.org/10.3389/ fevo.2019.00337.

Moreno, M., Semprucci, F., Vezzulli, L., Balsamo, M., Fabiano, M., Albertelli, G., 2011. The use of nematodes in assessing ecological quality status in the Mediterranean coastal ecosystems. Ecol. Indic. 11, 328-336. http://dx.doi.org/ 10.1016/j.ecolind.2010.05.011.

Nascimento, F.J.A., Karlson, A.M.L., Elmgren, R., 2008. Settling blooms of filamentous cyanobacteria as food for meiofauna communities. Limnol. Oceanogr. 53, 2636-2643. http://dx.doi.org/10.4319/lo.2008.53.6.2636.

Nascimento, F.J.A., Lallias, D., Bik, H.M., Creer, S., 2018. Sample size effects on the assessment of eukaryotic diversity and community structure in aquatic sediments using high-throughput sequencing. Sci. Rep. 8, 11737. http://dx.doi.org/10.1038/s41598-018-30179-1.
Newman, M.E.J., 2004. Fast algorithm for detecting community structure in networks. Phys. Rev. E http://dx.doi.org/10.1103/PhysRevE.69.066133.

Newman, M.E.J., Girvan, M., 2004. Finding and evaluating community structure in networks. Phys. Rev. E 69, 066133. http://dx.doi.org/10.1103/PhysRevE.69. 026113.

Oksanen, J., Blanchet, F.G., Kindt, R., Legendre, P., Minchin, P.R., O'Hara, R.B., Simpson, G.L., Solymos, P., Stevens, M.H.H., Wagner, H., 2013. Package 'Vegan'. R Packag. Ver. 2.5-2. http://dx.doi.org/10.4135/9781412971874.n145.

Pavan-Kumar, A., Gireesh-Babu, P., Lakra, W.S., 2015. NA Metabarcoding: A new approach for rapid biodiversity assessment. J. Cell Sci. Molecul. Biol. 2 (1) 111.

Pawlowski, J., Bolivar, I., Guiard-Maffia, J., Gouy, M., 1994. Phylogenetic position of foraminifera inferred from LSU rRNA gene sequences. Mol. Biol. Evol. 11, 929-938. http://dx.doi.org/10.1093/oxfordjournals.molbev.a040174.

Poisot, T., Canard, E., Mouillot, D., Mouquet, N., Gravel, D., 2012. The dissimilarity of species interaction networks. Ecol. Lett. 15 (12), 1353-1361. http://dx.doi org/10.1111/ele.12002.

Pusceddu, A., Gambi, C., Manini, E., Danovaro, R., 2007. Trophic state, ecosystem efficiency and biodiversity of transitional aquatic ecosystems: Analysis of environmental quality based on different benthic indicators. Chem. Ecol. 23 , 505-515. http://dx.doi.org/10.1080/02757540701760494.

R. Development Core Team, 2018. R: a Language and Environment for Statistical Computing. http://www.R-project.org/.

Rognes, T., Flouri, T., Nichols, B., Quince, C., Mahé, F., 2016. VSEARCH: a versatile open source tool for metagenomics. PeerJ 4, e2584. http://dx.doi.org/10.7717/ peerj.2584.

Rosenfeld, J.S., 2002. Functional redundancy in ecology and conservation. Oikos 98 (1), 156-162. http://dx.doi.org/10.1034/j.1600-0706.2002.980116.x.

Sander, E.L., Wootton, J.T., Allesina, S., 2017. Ecological network inference from long-term presence-absence data. Sci. Rep. 7, 7154. http://dx.doi.org/10.1038/ s41598-017-07009-x.

Santos, P.J.P., Castel, J., Souza-Santos, L.P., 1996. Seasonal variability of meiofaunal abundance in the oligo-mesohaline area of the Gironde Estuary. France. Estuar. Coast. Shelf Sci. 43, 549-563. http://dx.doi.org/10.1006/ecss.1996. 0087.

Schloss, P.D., Westcott, S.L., Ryabin, T., Hall, J.R., Hartmann, M., Hollister, E.B. Lesniewski, R.A., Oakley, B.B., Parks, D.H., Robinson, C.J., Sahl, J.W., Stres, B. Thallinger, G.G., Van Horn, D.J., Weber, C.F., 2009. Introducing mothur: Opensource, platform-independent, community-supported software for describing and comparing microbial communities. Appl. Environ. Microbiol. 75 (23) 7537-7541. http://dx.doi.org/10.1128/AEM.01541-09.

Schmieder, R., Edwards, R., 2011. Quality control and preprocessing of metagenomic datasets. Bioinformatics 27, 863-864. http://dx.doi.org/10. 1093/bioinformatics/btr026.

Schratzberger, M., 2012. On the relevance of meiobenthic research for policy-makers. Mar. Pollut. Bull. 64, 2639-2644. http://dx.doi.org/10.1016/ j.marpolbul.2012.08.028.

Schratzberger, M., Ingels, J., 2018. Meiofauna Matters: the roles of meiofauna in benthic ecosystems. J. Exp. Mar. Biol. Ecol. 502, 12-25. http://dx.doi.org/10. 1016/j.jembe.2017.01.007.

Smyth, K., Elliot, K., 2016. Chapter 9: Effects of changing salinity on the ecology of the marine environment. In: Solan, Martin, Whiteley, Nia M. (Eds.) Stressors in the Marine Environment. Oxford University Press.

Sousa, R., Dias, S., Antunes, J.C., 2006. Spatial subtidal macrobenthic distribution in relation to abiotic conditions in the Lima estuary, NW of Portugal. Hydrobiologia 559, 135-148. http://dx.doi.org/10.1007/s10750-005-1371-2.

Sousa, R., Dias, S., Antunes, J.C., 2007. Subtidal macrobenthic structure in the lower lima estuary, NW of Iberian Peninsula. Aquat. Conserv. Ann. Zool. Fennici 44 (4), 303-313. http://dx.doi.org/10.1002/aqc.

Sousa, R., Dias, S., Freitas, V., Antunes, C., 2008. Subtidal macrozoobenthic assemblages along the River Minho estuarine gradient (north-west Iberian Peninsula). Aquat. Conserv. 18, 1063-1077. http://dx.doi.org/10.1002/aqc. 871.

Stoeck, T., Bass, D., Nebel, M., Christen, R., Jones, M.D.M., Breiner, H.W. Richards, T.A., 2010. Multiple marker parallel tag environmental DNA sequencing reveals a highly complex eukaryotic community in marine anoxic water. Mol. Ecol. 19, 21-31. http://dx.doi.org/10.1111/j.1365-294X. 2009.04480.x.

Sun, P., Huang, L., Xu, D., Huang, B., Chen, N., Warren, A., 2017. Marked seasonality and high spatial variation in estuarine ciliates are driven by exchanges between the 'abundant' and 'intermediate' biospheres. Sci. Rep. 7, 1-12. http://dx.doi.org/10.1038/s41598-017-10308-y.

Taberlet, P., Bonin, A., Zinger, L., Coissac, E., 2018. Environmental DNA: For Biodiversity Research and Monitoring, first ed. Oxford University Press, Oxford and New York, http://dx.doi.org/10.1093/oso/9780198767220.001.0001.

Tang, C.Q., Leasi, F., Obertegger, U., Kieneke, A., Barraclough, T.G., Fontaneto, D. 2012. The widely used small subunit 18 S rDNA molecule greatly underestimates true diversity in biodiversity surveys of the meiofauna. Proc. Natl. Acad. Sci. USA 109 (40), 16208-16212.

Tange, O., 2011. GNU Parallel: The command-line power tool. login: 36, 42-47. 
Toju, H., 2015. High-throughput DNA barcoding for ecological network studies. Popul. Ecol. 57, 37-51. http://dx.doi.org/10.1007/s10144-014-0472-z.

Tulloch, A.I.T., Chadès, I., Lindenmayer, D.B., 2018. Species co-occurrence analysis predicts management outcomes for multiple threats. Nat. Ecol. Evol. 2, 465-474. http://dx.doi.org/10.1038/s41559-017-0457-3.

Tuomisto, H., 2010. A diversity of beta diversities: straighten- ing up a concept gone awry. Part 2. Quantifying beta diversity and related phenomena. Ecography 33, 23-45.

Ürkmez, D., Sezgin, M., Bat, L., 2015. Use of nematode maturity index for the determination of ecological quality status: a case study from the Black Sea. J. Black Sea/Mediterr. Environ. 20, 96-107.

Veech, J.A., 2013. A probabilistic model for analysing species co-occurrence. Glob. Ecol. Biogeogr. http://dx.doi.org/10.1111/j.1466-8238.2012.00789.x.

Vieira, J.M.P., Pinho, J.L.S., 2010. Salt distribution in river Lima Estuary for different hydrodinamic regimes. Assoc. Port. dos Recur. Hidrícos 31, 5-14.

Weigand, H., Beermann, A.J., Čiampor, F., Costa, F.O., Csabai, Z., Duarte, S. Geiger, M.F., Grabowski, M., Rimet, F., Rulik, B., Strand, M., Szucsich, N., Weigand, A.M., Willassen, E., Wyler, S.A., Bouchez, A., Borja, A., Čiamporová Zaťovičová, Z., Ferreira, S., Dijkstra, K.D.B., Eisendle, U., Freyhof, J., Gadawski, P., Graf, W., Haegerbaeumer, A., van der Hoorn, B.B., Japoshvili, B., Keresztes, L., Keskin, E., Leese, F., Macher, J.N., Mamos, T., Paz, G., Pešić, V., Pfannkuchen, D.M., Pfannkuchen, M.A., Price, B.W., Rinkevich, B., Teixeira, M.A.L., Várbíró, G., Ekrem, T., 2019. DNA Barcode reference libraries for the monitoring of aquatic biota in Europe: Gap-analysis and recommendations for future work. Sci. Total Environ. 678, 499-524. http://dx.doi.org 10.1016/j.scitotenv.2019.04.247.
Wobbrock, J.O., Findlater, L., Gergle, D., Higgins, J.J., 2011. The Aligned Rank Transform for nonparametric factorial analyses using only ANOVA procedures. In: Conference on Human Factors in Computing Systems Proceedings, pp. 143-146. http://dx.doi.org/10.1145/1978942.1978963.

Worsaee, K., Kerbl, A., Vang, A., Gonzalez, B.C., 2019. Broad North Atlantic distribution of a meiobenthic annelid - against all odds. Sci. Rep. 9 (1), 15497. http://dx.doi.org/10.1038/s41598-019-51765-x.

Zeppilli, D., Leduc, D., 2018. Biodiversity and ecology of meiofauna in extreme and changing environments. Mar. Biodivers. 48, 1-4. http://dx.doi.org/10. 1007/s12526-017-0840-y.

Zeppilli, D., Sarrazin, J., Leduc, D., Arbizu, P.M., Fontaneto, D., Fontanier, C., Gooday, A.J., Kristensen, R.M., Ivanenko, V.N., Sørensen, M.V., Vanreusel, A., Thébault, J., Mea, M., Allio, N., Andro, T., Arvigo, A., Castrec, J., Danielo, M., Foulon, V., Fumeron, R., Hermabessiere, L., Hulot, V., James, T., LangonneAugen, R., Le Bot, T., Long, M., Mahabror, D., Morel, Q., Pantalos, M., Pouplard, E., Raimondeau, L., Rio-Cabello, A., Seite, S., Traisnel, G., Urvoy, K., Stegen, T.Van.Der., Weyand, M., Fernandes, D., 2015. Is the meiofauna a good indicator for climate change and anthropogenic impacts? Mar. Biodivers. 45, 505-535. http://dx.doi.org/10.1007/s12526-015-0359-z.

Zinger, L., Bonin, A., Alsos, I.G., et al., 2019. DNA Metabarcoding-need for robust experimental designs to draw sound ecological conclusions. Mol Ecol. 28 (8), 1857-1862. http://dx.doi.org/10.1111/mec.15060. 